\title{
Adeno-associated viral vector-mediated human vascular endothelial growth factor gene transfer stimulates angiogenesis and wound healing in the genetically diabetic mouse
}

\author{
M. Galeano ${ }^{2}$, B. Deodato ${ }^{1,4}$, D. Altavilla ${ }^{1}$, D. Cucinotta ${ }^{3}$, N. Arsic ${ }^{4}$, H. Marini' ${ }^{1}$, V. Torre ${ }^{5}$, M. Giacca ${ }^{4}$, \\ F. Squadrito ${ }^{1}$ \\ ${ }^{1}$ Department of Clinical and Experimental Medicine and Pharmacology, Section of Pharmacology, \\ Azienda Ospedaliera Universitario “G. Martino”, Messina, Italy \\ 2 Department of Surgical Sciences, Section of Plastic Surgery, University of Messina, Italy \\ ${ }^{3}$ Department of Internal Medicine, Section of Metabolic Diseases, University of Messina, Italy \\ ${ }^{4}$ Molecular Medicine Laboratory, International Centre for Genetic Engineering and Biotechnology (ICGEB), Trieste, Italy \\ ${ }^{5}$ Unit of Pathology, F. Veneziale Hospital, Isernia, Italy
}

\begin{abstract}
Aims/hypothesis. We studied the gene therapy efficacy of diabetes-associated wound healing disorder with an adeno-associated virus (AAV) vector expressing the 165-amino acid isoform of human vascular endothelial growth factor-A (VEGF-A) by using an incisional skin-wound model produced on the back of female diabetic C57BL/KsJ $d b+/ d b+$ mice and their normal littermates $(d b+/+m)$.

Methods. Animals were randomized to receive intradermally into the wound edges either rAAV-LacZ (a control gene), or rAAV-VEGF165. Animals were killed on different days (7 and 14 days after skin injury) and wounded skin tissues were used for gene marker studies, histological evaluation and immunohistochemistry, and wound breaking strength analysis. Furthermore we studied the VEGF mature protein in the wounds.

Results. We found that AAV vectors are highly efficient for gene transfer to the mouse skin, displaying an exquisite tropism for the panniculus carnosus by
\end{abstract}

using the beta-galactosidase activity assay. We confirmed the increased expression of the angiogenic factor at day 7 by measuring the wound content of the mature protein. Delivery of VEGF165 to incisional skin wounds of diabetic mice resulted in a remarkable induction of new vessel formation with consequent improvement in the wound healing process. The rAAV-VEGF165 gene improved wound healing in diabetic mice through the stimulation of angiogenesis, reepithelization, synthesis and maturation of extracellular matrix. Moreover the recombinant AAV encoding the human VEGF165 increased the breaking strenght of the wound and enhanced the wound content of VEGF.

Conclusion/interpretation. Our study suggests that VEGF gene transfer might represent a new approach to treat wound healing disorders associated with diabetes. [Diabetologia (2003) 46:546-555]

Keywords Adeno-associated virus, angiogenesis, diabetes, gene therapy, VEGF, wound healing.
Received: 17 May 2002 / Revised: 24 October 2002

Published online: 2 April 2003

(C) Springer-Verlag 2003

Corresponding author: F. Squadrito MD, Department of Clinical and Experimental Medicine and Pharmacology, Section of Pharmacology, Azienda Ospedaliera Universitario "G. Martino", Torre Biologica 5th Floor, Via Consolare Valeria Gazzi, 98100 Messina, Italy

E-mail: Francesco.Squadrito@unime.it

Abbreviations: AAV, adeno-associated virus; VEGF, vascular endothelial growth factor; $\mathrm{db}+\mathrm{db}+$, diabetic mice; $\mathrm{db}+/+\mathrm{m}$, control mice.

M. Galeano and B. Deodato contributed equally to this article

\section{Introduction}

The process of wound healing involves a complex interplay of cells, mediators, growth factors and cytokines [1]. The cascade of events begins with clotting and recruitment of inflammatory cells, then proceeds as the wound enters a highly proliferative state. During this proliferative phase fibroblasts produce a collagen matrix, keratinocytes spread across the wound to form a new epithelial layer, and angiogenesis occurs. All the cells involved mediate their functions by the release of a variety of soluble factors controlling, in a cell type-specific manner, cellular activation and pro- 
liferation in the wound space, remodelling of extracellular matrix and collagen deposition in the injured area, as well as angiogenesis in the granulation tissue.

Angiogenesis is a crucial step in the healing process [2]. The formation of new blood vessels provides a route for oxygen and nutrient delivery, as well as a conduit for components of the inflammatory response. Healing is concomitant with an increasing release of angiogenic growth factors from macrophages and keratinocytes and its impairment leads to a delay in skin repair $[3,4,5,6,7]$. Vascular endothelial growth factor (VEGF) is one of the most potent angiogenic cytokines which promotes all steps in the angiogenic cascade [8]. In particular, it induces dissolution of the extracellular matrix, causes chemotaxis and proliferation of capillary endothelial cells and also promotes tube proliferation of endothelial cells. VEGF action is associated with a variety of physiological and pathological neovascular events such as embryonic development, tumor growth and wound repair as well [9]. VEGF is related to platelet-derived growth factor and has four different isoforms, $\mathrm{VEGF}_{121}, \mathrm{VEGF}_{165}, \mathrm{VEGF}_{189}$, $\mathrm{VEGF}_{206}$, which are generated by alternative splicing of mRNA [10]. VEGF is produced by keratinocytes that represent together with macrophages the most important source of this growth factor during normal wound healing.

Impaired wound healing could be a consequence of normal aging, metabolic derangement such as diabetes, or therapeutic interventions [11].

Genetically diabetic mice ( $d b / d b$ mice) are useful as an animal model for wound healing studies because wound healing in these animals is markedly delayed when compared with non-diabetic littermates $[12,13]$. Healing impairment is characterized by delayed cellular infiltration and granulation tissue formation, reduced angiogenesis, decreased collagen deposition and organization $[14,15,16,17]$. One of the mechanism underlying the healing impairment in diabetic mice is thought to result from a defect in VEGF regulation, during gene expression [18]. As a result, a reasonable approach to stimulate wound healing could be the topical application of growth factors. Although the results in animal studies are encouraging [19], topical treatment with growth factors in the clinical setting is limited by several factors, such as their short halflives, their inactivation by wound proteases, their poor bioavailability from the utilized vehicles, and consequently the need for daily applications and high initial doses that might become toxic. Thus, preliminary clinical trials have not produced the expected results $[20,21]$. An alternative approach that might overcome most of these problems is the topical delivery of growth factor-encoding genes into the relevant cells in the wound microenvironment. In this respect, skin wounds represent an attractive readily accessible target for therapeutic gene manipulation because wounds are readily accessible [22]. Several gene delivery pro- cedures have been used to investigate cutaneous gene transfer in vivo, including the use of viral and non-viral methods [23, 24]. Among the new strategies that hold promise for therapeutic gene therapy applications in the skin is the use of vectors based on the adeno-associated virus (AAV). These vectors are derived from a non-pathogenic and widespread defective parvovirus, and are able to transduce dividing and non-dividing cells, including skeletal and cardiac muscle [25, 26], brain [27] and liver [28]. Since recombinant AAV (rAAV) vectors are devoid of any viral genes, they virtually elicit no inflammatory or immune response in the sites of injection [29]. The aim of this study is to assess the capacity of recombinant AAV vector encoding the 165 amino acid isoform of vascular endothelial growth factor-A (VEGF-A) to promote wound repair in genetically healing-impaired diabetic mice.

\section{Materials and methods}

rAAV vector preparation and characterization. Two recombinant AAV vectors were obtained in this study, expressing the LacZ reporter gene (control gene) and the cDNA for the 165 amino-acid isoform of VEGF (VEGF165) under the control of the strong and constitutive cytomegalovirus (CMV) immediate early promoter. Both constructs were based on plasmid pFU-5, kindly provided by N. Muzyczka (University of Florida, Gainesville, Fla.,USA) [30]. pAAV-LacZ was obtained by substituting the GFP open reading frame with the LacZ gene from plasmid pCH110 (Pharmacia, Uppsala, Sweden).

The cDNA for VEGF165 was obtained by RT-PCR amplification of HL-60 total RNA with appropriate primer pairs and again cloned to replace GFP in the pFU-5 vector digested with Bam HI and Eco RI. Infectious vector stocks were generated in 293 cells, cultured in 150-mm-diameter Petri dishes, by cotransfecting each plate with $15 \mu \mathrm{g}$ of each vector plasmid, together with $45 \mu \mathrm{g}$ of the packaging/helper plasmid, pDG (kindly provided by J.A. Kleinschmidt) expressing AAV and adenovirus helper functions [31]. Twelve hours after transfection, the medium was replaced by fresh medium and 3 days later the medium was collected and the cells harvested by scraping.

After three freeze-thaw cycles in dry ice/ethanol bath and $37^{\circ} \mathrm{C}$ water bath, cell lysates were fractionated using ammonium sulfate precipitation. rAAV particles were then purified by $\mathrm{CsCl}$ gradient centrifugation in a SW41Ti rotor at $288,000 \times \mathrm{g}$ for $36 \mathrm{~h}$. Twelve to sixteen fractions of ten drops each were collected by inserting a G-21 needle below the rAAV band and their refractive index was determined. The six fractions with index closest to 1.3715 (corresponding to a density of $1.40 \mathrm{~g} / \mathrm{cm}^{3}$ ) were dialiyzed against phosphate buffered saline (PBS) at $4^{\circ} \mathrm{C}$ overnight and stored at $-80^{\circ} \mathrm{C}$. rAAV titres were determined by measuring the copy number of viral genomes in pooled, dialyzed gradient fractions. This was achieved by a competitive PCR procedure [32] using primers and competitors mapping in the CMV promoter region common to all vectors. The purified viral preparations used for this work had particle titres of about $1 \times 10^{12}$ viral genomes per $\mathrm{ml}$. The infectious titre in this preparation is usually 100 to 1000 times less, depending on either the type of preparation and the transduced tissue.

Animals and experimental protocol. All animal procedures were in accordance with the declaration of Helsinki and with the Guide for the Care and Use of Laboratory Animals. 
Table 1. Criteria to evaluate histological scores of wound healing

\begin{tabular}{|c|c|c|c|}
\hline Scores & Epidermal and dermal regeneration & Granulation tissue thickness & Angiogenesis \\
\hline $1 \pm$ & $\begin{array}{l}\text { Little epidermal and dermal } \\
\text { organization }\end{array}$ & Thin granulation layer & $\begin{array}{l}\text { Altered angiogenesis ( } 1-2 \text { vessels per site) } \\
\text { characterized by a high degree of oedema, } \\
\text { haemorrhage, occasional congestion } \\
\text { and thrombosis }\end{array}$ \\
\hline $2 \pm$ & $\begin{array}{l}\text { Moderate epidermal } \\
\text { and dermal organization }\end{array}$ & Moderate granulation layer & $\begin{array}{l}\text { Few newly formed capillary vessels } \\
\text { ( } 3-4 \text { per site); moderate degree } \\
\text { of oedema and haemorrhage. } \\
\text { Occasional congestion and intervascular } \\
\text { fibrin deposition; absence of thrombosis }\end{array}$ \\
\hline $3 \pm$ & $\begin{array}{l}\text { Complete remodeling } \\
\text { of epidermis and dermis }\end{array}$ & Thick granulation layer & $\begin{array}{l}\text { Newly-formed capillary vessels } \\
\text { (5-6 per site); moderate degree } \\
\text { of perivascular and interstitial oedema } \\
\text { and congestion. Absence of thrombosis } \\
\text { and haemorrhage }\end{array}$ \\
\hline
\end{tabular}

Genetically diabetic female C57BL/KsJ $d b+/ d b+$ mice and the control mice $(d b+/+m)$ were obtained from Jackson Laboratory (Bar Harbor, Maine USA). Animals were 14 weeks old at the start of the experiments. Diabetic mice were obese, weighing 40 to50 g, hyperglycaemic with average glucose concentrations of $527 \pm 25 \mathrm{mg} / \mathrm{dl}$. The hyperglycaemia produced classic signs of diabetes, including polydipsia, polyuria, and glycosuria.

During the experiments the animals were housed one per cage, maintained under controlled environmental conditions (12 h light to dark cycle, temperature approximately $23^{\circ} \mathrm{C}$ ) and provided with standard laboratory food and water ad libitum.

After general anesthesia with ketamine hydrochloride $(110 \mathrm{mg} / \mathrm{kg})$, hair on the back was shaved and skin washed with povidone-iodine solution and wiped with sterile water. Two full-thickness longitudinal incisions $(4 \mathrm{~cm})$ were made on the dorsum of the mice and the wound edges were closed with skin clips placed at $1-\mathrm{cm}$ intervals. Wounded genetically diabetic female $\mathrm{C} 57 \mathrm{BL} / \mathrm{KsJ} d b+/ d b+$ mice and the control mice $(d b+/+m)$ were randomized to receive either rAAV-VEGF165 or rAAV-LacZ (a control and inert gene). The viral suspension was injected intradermally into the wound edges using $1 \mathrm{cc}$ syringe and 30 gauge needle; five to seven injections of about $20 \mu \mathrm{l}$ each (corresponding to $\sim 10^{11}$ vector particles) per wound were administered. Animals for each group were killed after 7 and 14 days respectively and the wounds were divided into three segments $(0.8 \mathrm{~cm}$ wide). The caudal and cranial strip was used for histology and for the evaluation of $\beta$-galactosidase while the central one was used for molecular analysis, VEGF content and wound breaking strength measurements (only day 14). Moreover another set of animals $(d b+/ d b+$ mice and the control mice $d b+/+m$ treated either with rAAV-VEGF165 or rAAV-LacZ) was killed at day 28 or alternatively when skin normalization was completed to evaluate histologically skin maturation and the VEGF wound content.

Detection of beta-galactosidase activity. Wounds collected at day 7 and 14 were briefly washed in cold PBS supplemented with $0.02 \%$ NP40, fixed in $2 \%$ buffered paraformaldehyde and
$0.02 \%$ NP40 for $45 \mathrm{~min}$ at room temperature, washed again in PBS and immersed in a solution containing $1 \mathrm{mg} / \mathrm{ml} \mathrm{X}$-gal, $2 \mathrm{mmol} / \mathrm{l} \mathrm{MgCl} 2,5 \mathrm{mmol} / \mathrm{l} \mathrm{K} 3 \mathrm{Fe}(\mathrm{Cn}) 6,5 \mathrm{mmol} / \mathrm{l} \mathrm{K} 4 \mathrm{Fe}(\mathrm{Cn}) 6$, $0.02 \%$ NP40 in PBS at $37^{\circ} \mathrm{C}$ overnight. Tissue samples were then rinsed in PBS, fixed in $4 \%$ formaldehyde, embedded in paraffin, cut into $5 \mu \mathrm{m}$ thick sections, mounted onto slides and counterstained with nuclear fast red.

Histological evaluation. The samples were fixed in $10 \%$ buffered formalin for light microscopic examination. After fixation, perpendicular sections to the anterior-posterior axis of the wound were dehydrated with graded ethanols and embedded in paraffin. Five-micron thick sections were mounted on glass slides, rehydrated to distilled water and stained with haematoxylin and eosin. As part of the histological evaluation, all slides were examined by a pathologist without knowledge of the previous treatment, using masked slides under the microscope from $\times 20$ to $\times 100$ magnification. The following parameters were evaluated: epidermal and dermal regeneration, granulation tissue formation, and angiogenesis. The margins of the wound in each of the sections as well as normal control wounds were used as comparison for scoring (Table 1). Concerning angiogenesis, only mature vessels that contained erythrocytes were counted. To evaluate well-formed from poorlyformed capillary vessels the following parameters were considered: presence or absence of oedema, congestion, haemorrhage, thrombosis and intravascular or intervascular fibrin formation. The histological score adopted in this study was evaluated according to data regarding wound healing in experimental models [18, 33].

Breaking strength. The maximum load (breaking strength) tolerated by wounds was measured blindly on coded samples using a calibrated tensometer (Instron Corp, Canton, Mass., USA) as described previously [34]. The ends of the skin strip were pulled at a constant speed $(20 \mathrm{~cm} / \mathrm{min})$, and breaking strength was expressed as the mean maximum level of tensile strength $(\mathrm{g} / \mathrm{mm})$ before separation of wounds. 
Determination of VEGF in wounds. The amount of VEGF in wounds was determined by ELISA. Briefly tissue were homogenized in $1.0 \mathrm{ml}$ of $1 \times$ PBS containing Complete Protease Inhibitor Cocktail (Boehringer Mannhein, Indianapolis, Ind., USA). Homogenates were centrifuged to remove debris, and filtered through a $1.2 \mu \mathrm{m}$ pore syringe filter. Analysis was done with commercially available human VEGF specific ELISA kit. The amount of VEGF was expressed as pg/wound.

Statistical analysis. All data were analysed by Student's $t$ test. The results were expressed as means \pm SE. The level for statistical significance was set at a $p$ value of less than 0.05 .

\section{Results}

Transgene expression of rAAV vectors in the wounds. To study the location and the time course of rAAV expression in wounds, beta-galactosidase activity was determined by histological analysis. At day 7 on histological sections, weak beta-galactosidase activity was observed in hair follicles, while high LacZ expression was mostly evident in the panniculus carnosus, a layer

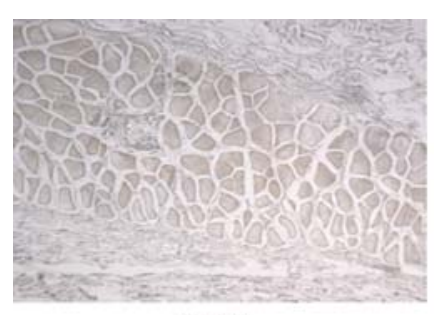

PBS

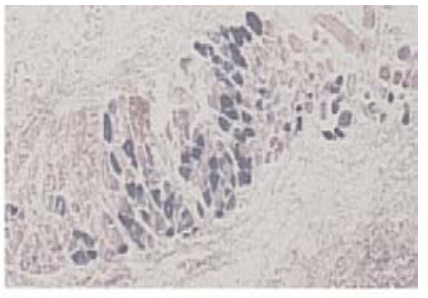

rAAV-LacZ
Fig. 1. Transduction of mouse skin wounds with rAAV-LacZ. Histological examination of recombinant rAAV-LacZ $\left(\sim 10^{11}\right.$ particles) or PBS injected mouse skin wounds. High expression of beta-galactosidase was detected in muscular cells of the panniculus carnosus 7 days after gene delivery of skeletal muscle underlying the dermis where it reached its highest intensity (Fig. 1). In contrast, staining of dermal fibroblasts was rare. No beta-galoctosidase activity was observed in skin wounds treated with PBS (Fig. 1).

VEGF levels in wound. We investigated the levels of the angiogenic factor by a specific immunoElisa for human VEGF165 in wound specimens collected 7 and 14 days after treatment of the skin wounds with rAAV-LaCZ or the recombinant AAV vector encoding the human anigiogenic factor. The gene transfer of VEGF increased the levels of the mature protein in the wounds in both strains of mice (Fig. 2).

The gene transfer caused marked production of VEGF at day 7 either in normoglycaemic animals (rAAV-LacZ $=13 \pm 3 \mathrm{pg}$ /wound; rAAV-VEGF165 72 \pm $8 \mathrm{pg} /$ wound; $p<0.001, n=7)$ and in diabetic mice (rAAV-LacZ=10 \pm 2 pg/wound; rAAV-VEGF165= $80 \pm 9 \mathrm{pg} /$ wound; $p<0.001 ; n=7)$. Similar results were obtained at day 14 .

Transgene expression lasted up to 4 months. Furthermore the expression was confined to the skin: indeed no other tissue showed any sign of rAAV vectors transgene expression.

Promotion of neo-angiogenesis and improvement of diabetes impaired wound healing by rAAV-VEGF165. Figure 3 shows the histological scores of wounds throughout the experiment according to the criteria in Table 1.

Histological examination of diabetic wounds at day 7 showed incomplete re-epithelialization, crusting, and poorly-formed and immature granulation tissue formation (Fig. 4A). A prominent infiltration of inflammatory cells, mainly composed of neutrophils, within the wound margins and in deep dermis, were

\section{Wound VEGF content}

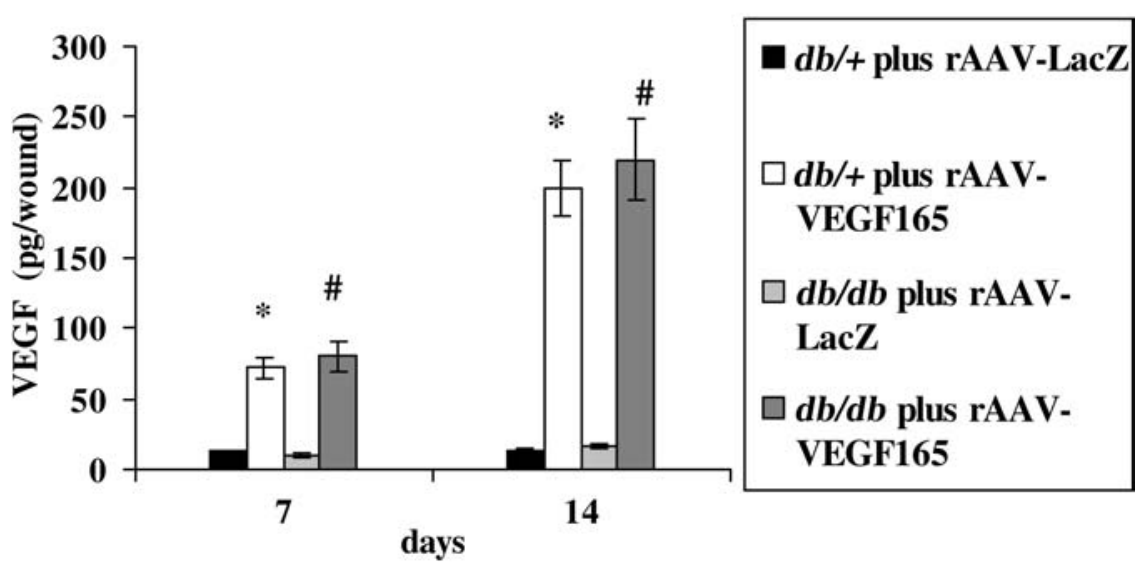

Fig. 2. Wound VEGF levels after rAAV-VEGF165 treatment. VEGF levels in wound specimens treated with rAAVboth $d b /+$ and $d b / d b$ mice. Each point represents the means \pm SE of seven experiments. $p<0.01 \mathrm{vs} d b / d b$ mice treated with VEGF165 ( 1011 particles) or rAAV-LacZ $\left(\sim 10^{11}\right.$ particles $)$ in rAAV-LacZ. $* p<0.05$ vs $d b /+$ mice treated with rAAV-LacZ 

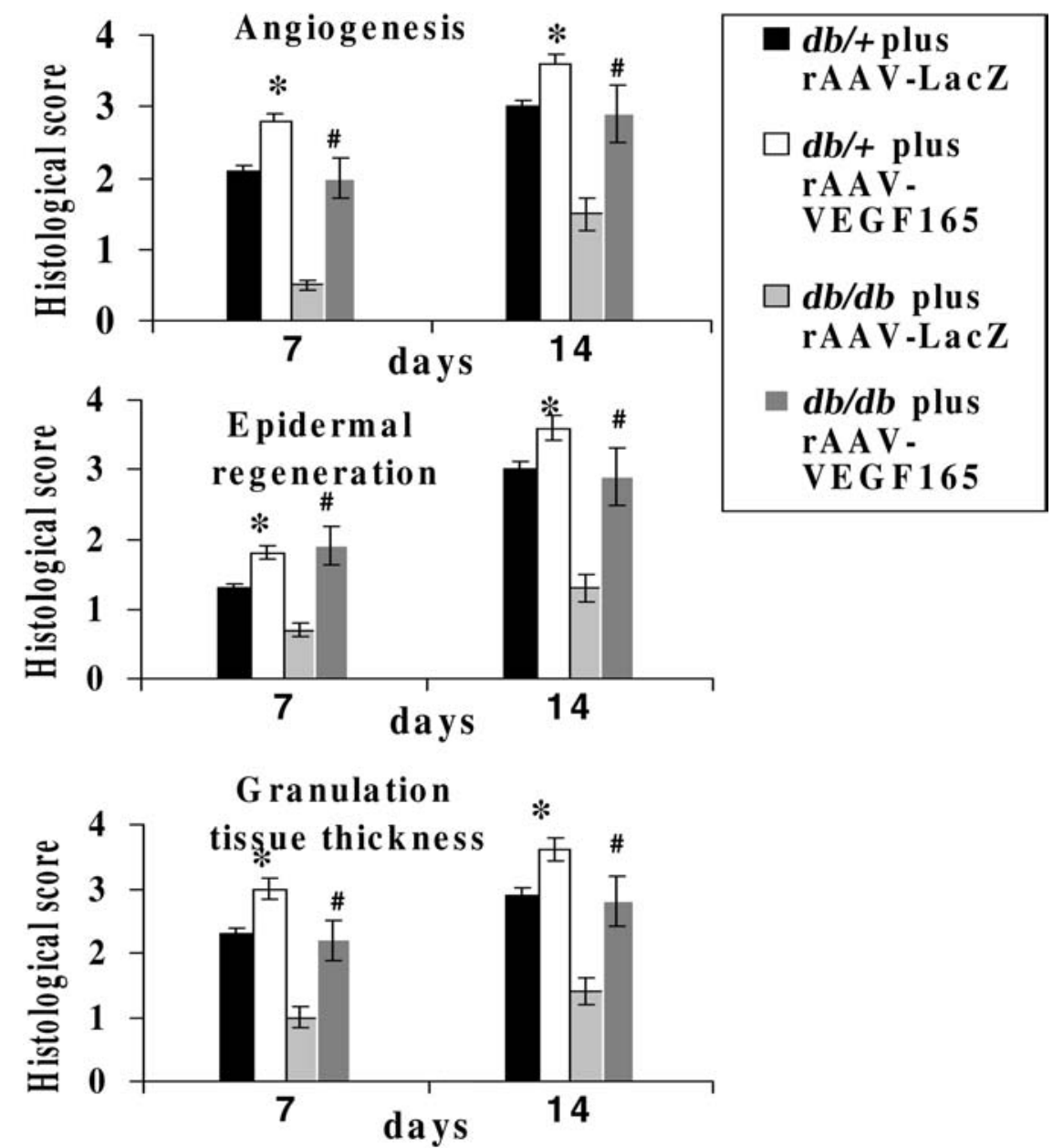

Fig. 3. Histological scores of wound healing after rAAVVEGF165 or rAAV-LacZ transduction. Assessment of wound healing in $d b /+$ and $d b / d b$ mice at day 7 and 14 after wounding and treatment with rAAV-VEGF165 or rAAV-LacZ, as indicated, according to the histological scores of Table 1. Each point represents the means $\pm \mathrm{SE}$ of seven experiments. $\# p<0.01$ vs $d b / d b$ mice treated with rAAV-LacZ. $* p<0.05$ vs $d b /+$ treated with rAAV-LacZ

observed. Tissue oedema and haemorrhage were evident. A low vascular count was characterized by few newly-formed capillaries (1-2 per site) and vascular dilation at the peripheral margins of the wound. Evidence of extravascular red blood cells, perivascular fibrin deposition, and an increase of the adipose tissue were factors in impaired healing.

Few differences characterized diabetic wounds treated with rAAVVEGF165 in comparison to diabetic wounds administered with the control and inert gene rAAV-LacZ at day 7 (Fig. 4B). Re-epithelialization was moderate, still persisting both focal spongiosis and scab. Granulation tissue appeared partially organized, with slight oedema and occasional vascular congestion. Angiogenesis ranged from a low (3-4 per site) to moderate (5-6) microfocal vessel count. A prominent distribution of newly-formed blood vessels was observed in the superficial or deep areas of the wound.
Diabetic wounds administered with rAAV-LacZ at day 14 were characterized by moderate re-epithelialization, and partially organized granulation tissue (Fig. 4C). A slight inflammatory infiltrate, the presence of adipose tissue within the scar, oedema and focal erythrorrhages were noted (Fig. 4D). Microvessels distribution gave a low to moderate count (3-5 per site). Groups of capillaries showed nuclear prominence and perivascular mononuclear cell infiltration.

On the other hand, moderate to complete re-epithelialization, well-formed granulation tissue and moderate to high vascular count ( 7 or more per site) were observed in diabetic wounds treated with rAAVVEGF165 at day 14 (Fig. 4E). Extensive tissue remodelling, absence of oedema and congestion, prominent distribution of capillaries within the superficial and deep areas of the granulation tissue were evident (Fig. 4F).

In normoglycaemic animals treated $(d b /+)$ with the control and inert gene rAAV-LacZ remodelling of the dermis and the wound closure process was complete. The healing process was qualitatively and quantitatively not different from that observed in PBS-treated wounds. This suggests that the vector does not impair the physiological mechanisms of wound healing. In addition, rAAV-VEGF165 injection into the wounds of non-diabetic animals improved wound closure (Fig. 3). 

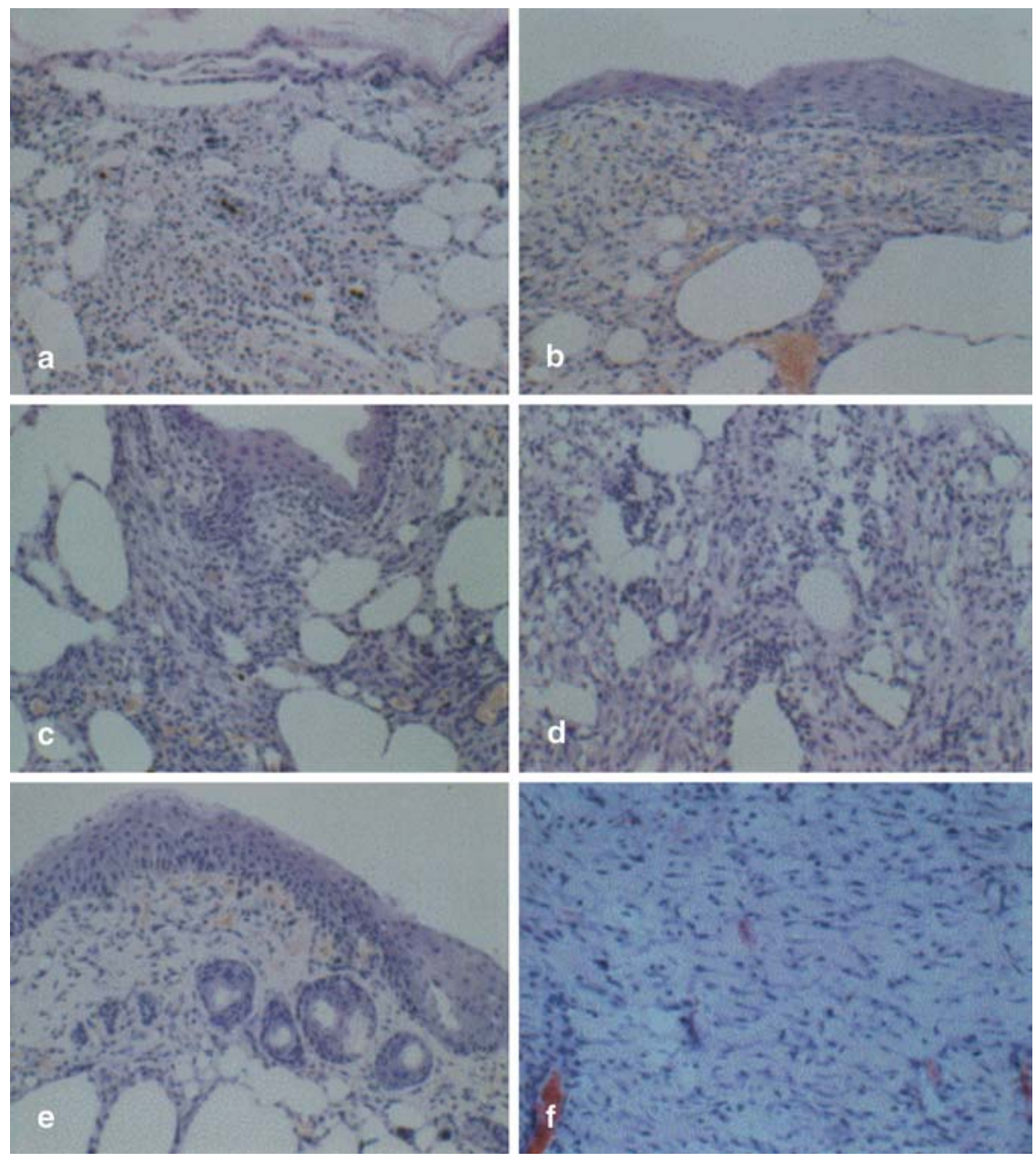

Fig. 4a-f. (Histological photomicrographs, haematoxylin-eosin, original magnification $\times 50$.) a rAAV-LacZ-treated diabetic wound at day 7. Thin and immature epithelial layer partially detached from the underline dermis and poorly-formed granulation tissue with inflammatory infiltrates but no newly-formed capillaries are shown. b rAAV-VEGF165-treated diabetic wound at day 7. A moderate re-epithelialization covers a partially organized granulation tissue with increased vascularization. c rAAV-LacZ-treated diabetic wound at day 14. Moderate re-epithelialization and granulation tissue organization with focal neovascularization and perivascular inflammatory infiltrates are observed. d rAAV-LacZ-treated diabetic wound at day 14. Particular of the granulation tissue characterized by inflammation, oedema and adipose tissue. e rAAV-VEGF165treated diabetic wound at day 14 . Re-epithelialization is almost complete with absence of spongiosis or crusting. A wellformed granulation tissue and numerous small blood vessels are noted especially in the superficial areas of the wound. $\mathbf{f}$ rAAV-VEGF165-treated diabetic wound at day 14. Particular of the granulation tissue with complete remodelling, good vascular count represented by newly-formed capillaries as well as vessels of a greater diameter, and no evidence of inflammation, oedema or erythrorrhagies

Breaking strength. The wound breaking strengths for each group at day 14 are shown (Fig. 5). The breaking strengths of incisional diabetic wounds treated with recombinant AAV vector encoding the human VEGF165 was higher than that of control diabetic

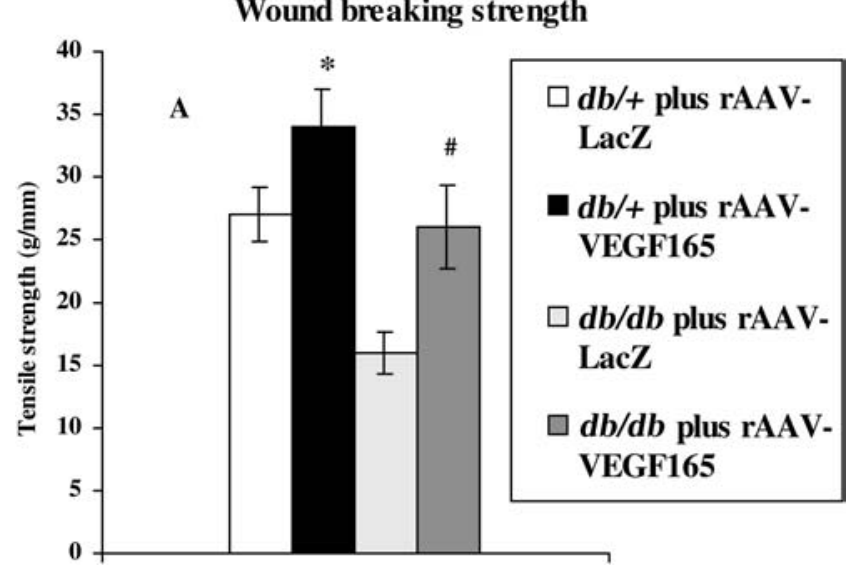

Fig. 5. Wound breaking strength after rAAV-VEGF165 treatment in $d b /+$ and $d b / d b$ mice. Tensile strength $(\mathrm{g} / \mathrm{mm})$ evaluated at day 14 in wounds treated with rAAV-VEGF165 $\left(\sim 10^{11}\right.$ particles) or rAAV-LacZ $\left(\sim 10^{11}\right.$ particles $)$ in both $d b /+$ and $d b / d b$ mice. Bar heights represent the means \pm SE of seven experiments. $\# p<0.01$ vs $d b / d b$ mice treated with rAAV-LacZ. $* p<0.05$ vs $d b /+$ mice treated with rAAV-LacZ

wounds given with rAAV-LacZ. Similar results were obtained in non-diabetic wounds (Fig. 5).

Skin normalization. Completed skin normalization occurred at day 22 after wounding in normoglycaemic 


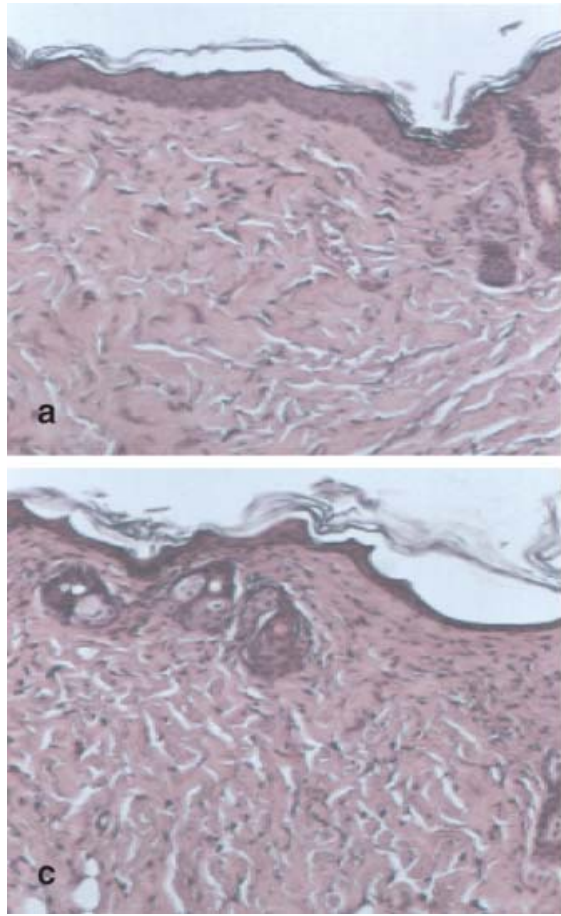

Fig. 6A-D. Photomicrographs of wound specimens from untreated non-diabetic mice (A) at 22 days, VEGF-treated nondiabetic animal (B) at 18 days, diabetic untreated mice $(\mathbf{C})$ at day 35 and VEGF-treated mice at day 28 (D). Each figure shows similar good wound healing with complete re-epithelialization and well-formed connective tissue. (a, b, c, d: haematoxylin and eosin; original magnification $\times 180$ )

mice treated with $\mathrm{rAAV}$ LacZ and at day 35 after wounding in diabetic mice treated with the vector alone (Fig. 6).

The gene transfer of VEGF reduced the time to skin normalization in either normoglycaemic (day 18) and diabetic mice (day 28). Furthermore skin normalization after rAAV-VEGF165 occurred without any sign of dysplasia with no hyperplastic or abnormal epidermis maturation (Fig. 6).

VEGF wound content at day 28 after wounding was $210 \pm 69 \mathrm{pg} /$ wound $(n=6)$ and $220 \pm 75 \mathrm{pg} /$ wound in rAAV-VEGF165 treated normoglyacaemic and diabetic mice, respectively; thus suggesting that there is a stabilization and no further increase in the levels of the angiogenic factor.

\section{Discussion}

Angiogenesis, together with cell migration, inflammation, provisional matrix synthesis, collagen deposition and re-epithelialization plays an integral role in the process of skin repair. During wound healing, angiogenic capillary sprouts invade the fibrin-fibronectinrich wound clot and organize into a microvascular networks throughout the granulation tissue.

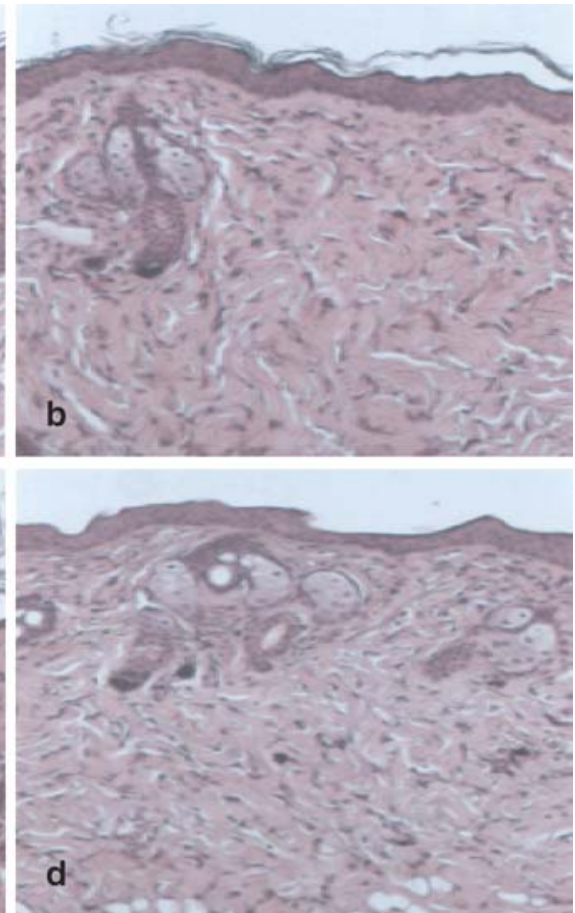

VEGF has been shown to play a pivotal role in the initiation of angiogenesis, based on its ability to induce the expression of proteases that digest components of the extracellular matrix that impede angiogenesis, to promote endothelial cell proliferation, and to prevent their apoptosis [35].

Experimental evidence has shown expression of VEGF and its receptors during wound healing [6]. Elevated VEGF mRNA levels were found in keratinocytes at the wound edges and in keratinocytes that migrate to cover the wound surface [36]. Besides, antibody neutralization of this cytokine was shown to inhibit formation of wound granulation tissue [37].

Impaired wound healing activity in diabetes could result from several factors including high blood glucose concentrations, blunted cell mediated immunity, local ischaemia and reactive oxygen intermediated production. The reduced oxygenation, such as that observed in local ischaemia, prompts the production of extremely reactive metabolites (free oxygen radicals) that impair normal wound healing by damaging keratinocytes, endothelial cells and collagen metabolism. The overproduction of free radicals in diabetes could also cause an impairment in the production and release of the powerful angiogenic factor VEGF. Experimental evidence from our laboratory have indicated that in genetically diabetic mice the mRNA levels of VEGF as well as the wound content of the mature angiogenic factor were severely reduced during the healing process [18]. Furthermore lipid peroxidation inhibition restored wound healing to nearly normal levels and normalized the defect in VEGF regulation associated with diabetes-induced skin-repair disorders [18]. It has been suggested that VEGF posttranslational processing requires the optimal function of the oxy- 
gen-regulated protein 150 (ORP-150) that might be impaired (because of a marked oxidative stress response) in experimental diabetes: local administration of an adenovirus encoding ORP150 to wounds of diabetic mice, markedly improved the wound healing process [38]. These findings further suggest that an impairment in VEGF regulation is associated with wound-healing abnormalities in diabetes.

Therefore, it seems that local treatment of wounds with VEGF protein or through VEGF gene transfer might represent an important tool to promote efficient wound repair in diabetes.

As far as treatment with VEGF protein or other growth factors is concerned, animal experiments and clinical trials have reported only modest improvements in wound closure, despite large repetitive doses, and a long duration of therapy [39, 40]. This would suggest that exogenous presentation can lead to clearance, sequestration [41] or destruction [42] of the factor.

In contrast, gene therapy could overcome the shortcomings of direct application of the growth factor and promote continual production and release of the growth factor within the wound site.

Among the vectors which can be considered for therapeutic application to skin, those based on AAV seem to possess several appealing features, including the capacity to promote long-term expression of the therapeutic gene in the absence of signs of inflammation or immune response. Apart from being able to transduce human keratinocytes in vitro [43], LacZ gene marker studies have shown that AAV transduction is highly efficient in the muscular tissue of the dermis (panniculus carnosus) of rodents [44] again reinforcing the notion of the exquisite tropism of these vectors for muscular cells [45]. Transduction of this tissue results in prolonged expression of the marker transgene and causes no apparent histological or functional change in the wound repair process.

Similar to LacZ, the injection of a rAAV encoding the 165-amino acid isoform of VEGF also resulted in prolonged expression of this cytokine, with the functional consequence of greatly increasing formation of new blood vessels in the wounded tissue.

In our study, an AAV vector encoding the 165-aa isoform of VEGF was used successfully in the induction of VEGF gene overexpression in experimental diabetes-impaired wounds. Expression of VEGF 165 enhanced wound repair, an event which correlated well with improvement of all the histological parameters which were considered, including epidermal and dermal regeneration, thickness of granulation tissue, and formation of well-structured capillary vessels.

The wound healing process of normoglycaemic animals was also improved by the gene transfer of human VEGF, as shown previously [46]. Furthermore PBS-treated wounds healed similarly to wounds treated with the control and inert gene rAAV-LacZ. This confirms that the virus vector does not alter the process of skin repair.

Indeed rAAV vectors seem to have a particular tropism for the skin: as a matter of fact transgene expression in the interfollicular epidermis and in the panniuclus carnosus, a layer of skeletal muscle underlying the dermis, is remarkable within 7 to 10 days [46]. In contrast experimental evidences suggest that the transgene expression of rAAV vectors in other tissues (such as the heart, brain and the liver) requires at least 3 to 4 weeks $[26,27,28]$.

The reason for this discrepancy is not completely understood: it could be hypothesized that the skin is exposed to some factor(s) that accelerate the insertion of the rAAV vectors into the genomic machinery. It has been suggested that UV, ionizing irradiation and the cellular redox state lead to the enhanced production and activation of cellular factors important in the conversion of single-stranded DNA genomes to expressible forms [47].

Furthermore the expression of rAAV vectors was confined to the skin, thus strongly suggesting the absence of any systemic effect of this gene therapy: that is of particular importance in the clinical setting where the long distance organs safety must be taken into particular account. This could represent and important advantage of AAV vectors. However transgene expression could last up to 4 months: as the long-lasting presence of the rAAV vectors could be a limitation and disadvantage of this gene therapy. Although a possibility does exist to drive the VEGF expression by an on-off switch mechanism through an antibiotic sensitive gene region. This can represent an attractive strategy to modulate the expression of the transduced gene and it would also allow increasing the compliance and the safety profile of skin-gene therapy [48, $49,50]$.

VEGF gene therapy with rAAV might also cause, because of long-term expression, an abnormal maturation of epidermis. To investigate this point we carried out histological analysis after complete skin normalization. Our results clearly suggest that skin normalization after rAAV-VEGF165 gene transfer occurs without any sign of dysplasia with no hyperplastic or abnormal epidermis maturation in both diabetic and non-diabetic mice. No quantitative or qualitative difference in skin maturation can be detected between treated and untreated animals. This could represent another appealing feature, if confirmed in human skin, of this gene therapy.

In conclusion, our results suggest that gene therapy with adeno-associated virus vectors encoding VEGF might be of particular relevance in the clinical situation of impaired and delayed wound repair that contribute to the development of diabetic ulcers. 


\section{References}

1. Clark RAF (1985) Cutaneous tissue repair: basic biologic consideration, I. J Am Acad Dermatol 13:701-725

2. Arnold F, West DC (1991) Angiogenesis in wound healing. Pharmacol Ther 52:407-422

3. Shukla A, Dubey MP, Srivastava R, Srivastava BS (1998) Differential expression of proteins during healing of cutaneous wounds in experimental normal and chronic models. Biochem Biophys Res Commun 244:434-439

4. Pierce GF, Tapley JE, Tseng J et al. (1995) Detection of platelet-derived growth factor (PDGF)-AA in actively healing human wounds treated with recombinant PDGF-BB and absence of PDGF in chronic nonhealing wounds. J Clin Invest 96:1336-1350

5. Werner S, Breeden M, Hubner G, Greenhalgh DL, Longaker MT (1994) Induction of keratinocyte growth factor expression is reduced and delayed during wound healing in the genetically diabetic mouse. J Invest Dermatol 103:469-473

6. Brown LF, Yeo KT, Verse B et al. (1992) Expression of vascular permeability factor (vascular endothelial growth factor) by epidermal keratinocytes during wound healing. J Exp Med 176:1375-1379

7. Ansel JC, Tiesman JP, Olerud JE et al. (1993) Human keratinocytes are a major source of cutaneous platelet-derived growth factor. J Clin Invest 92:671-678

8. Ferrara N (1999) Role of vascular endothelial growth factor in the regulation of angiogenesis. Kidney Int 56:794-814

9. Nissen NN, Dolverini PJ, Koch AE et al. (1998) Vascular endothelial growth factor mediates angiogenic activity during the proliferative phase of wound healing. Am J Pathol 152:1445-1452

10. Ferrara N (1998) Molecular and biological properties of vascular endothelial growth factor. J Mol Med 77:527-543

11. Stadelmann WK, Digenis AG, Tobin GR (1998) Impediments to wound healing. Am J Surg 176:39S-47S

12. Greenhalgh DG, Sprugel KH, Murray MJ, Ross R (1998) PDGF and FGF stimulate wound healing in the genetically diabetic mouse. Am J Pathol 136:1235-1246

13. Matuszewska B, Keogan M, Fisher et al. (1998) Acidic fibroblast growth factor: evaluation of topical formulations in a diabetic mouse wound healing model. Pharm Res 11:65-71

14. Coleman D-L (1982) Diabetes-obesity syndromes in mice. Diabetes 31 [Suppl 1]:1-6

15. Bohlen HG, Niggl BA (1979) Adult microvascular disturbances as a result of juvenile-onset diabetes in $\mathrm{db} / \mathrm{db}$ mice. Blood Vessels 16:269-276

16. Yue DK, McLennan S, Marsh M et al. (1987) Effects of experimental diabetes, uremia and malnutrition on wound healing. Diabetes 36:295-299

17. Goodson WH, Hunt TK (1977) Studies of wound healing in experimental diabetes. J Surg Res 22:221-227

18. Altavilla D, Saitta A, Cucinotta D et al. (2001) Inhibition of lipid peroxidation restores impaired vascular endothelial growth factor expression and stimulates wound healing and angiogenesis. Diabetes 50:667-674

19. Lawrence WT, Diegelmann RF (1994) Growth factors in wound healing. Clin Dermatol 12:157-169

20. Robson MC, Mustoe TA, Hunt TK (1998) The future of recombinant growth factors in wound healing. Am J Surg 176:80S-82S

21. Greenhalgh DG (1996)The role of growth factors in wound healing. J Trauma 41:159-167

22. Greenhalgh DA, Rothnagel JA, Roop DR (1994) Epidermis: an attractive target tissue for gene therapy. J Invest Dermatol 103:63S-69S
23. Ghazizadeh S, Taichman L-B (2000) Virus-mediated gene transfer for cutaneous gene therapy. Hum Gene Ther 11:2247-2251

24. Vogel J-C (2000) Non-viral skin gene therapy. Hum Gene Ther 11:2253-2259

25. Snyder RO, Spratt SK, Lagarde C et al. (1997) Efficient and stable adeno-associated virus-mediated transduction in the skeletal muscle of adult immunocompetent mice. Hum Gene Ther 8:1891-1900

26. Su H, Lu R, Kan YW (2000) Adeno-associated viral vector-mediated vascular endothelial growth factor gene transfer induces neovascular formation in ischemic heart. ProcNatl Acad Sci USA 97:13801-13806

27. Kaplitt MG, Leone P, Samulski RJ et al. (1994) Long-term gene expression and phenotypic correction using adenoassociated virus vectors in the mammalian brain. Nat Genet 8:148-154

28. Xiao W, Berta SC, Lu MM et al. (1998) Adeno-associated virus as a vector for liver-directed gene therapy. J Virol 72:10222-10226

29. Chirmule N, Propert K, Magosin J et al. (1999) Immune responses to adenovirus and adeno-associated virus in humans. Gene Ther 6:1574-1583

30. Zolotukhin S, Putter M, Hauswirth WW, Guy J, Muzyczka N (1996) A "humanized" green fluorescent protein cDNA adapted for high-level expression in mammalian cells. J Virol 70:4646-4654

31. Grimm D, Kern A, Rittner K, Kleinschmidt JA (1998) Novel tools for production and purification of recombinant adenoassociated virus vectors. Hum Gene Ther 9:2745-2760

32. Diviacco S, Norio P, Zentilin L et al. (1992) A novel procedure for quantitative polymerase chain reaction by coamplification of competitive templates. Gene 122:313-320

33. Niwano Y, Koga H, Sakai A et al. (1996) Wound healing effect of malotilate in rats. Arzneimittelforschung 46:450455

34. Pierce GF, Mustoe TA, Senior RM et al. (1988) In vivo incisional wound healing augmented by platelet-derived growth factor and recombinant c-cis gene homodimeric proteins. J Exp Med 167:974-987

35. Griffioen AW, Molema G (2000) Angiogenesis: potentials for pharmacologic intervention in the treatment of cancer, cardiovascular diseases, and chronic inflammation. Pharmacol Rev 52:237-268

36. Werner S, Peters KG, Longaker MT, Fueller-Pace F, Banda MJ, Williams LT (1992) Large induction of keratinocyte growth factor expression in dermis during wound healing. Proc Natl Acad Sci USA 89:6896-6900

37. Howdieshell TR, Callaway D, Webb WL et al (2001) Antibody neutralization of vascular endothelial growth factor inhibits wound granulation tissue formation. J Surg Res 96:173-182

38. Ozawa K, Kondo T, Hori O et al. (2001) Expression of the oxygen-regulated protein ORP150, accelerates wound healing by modulating intracellular VEGF transport. J Clin Invest 108:41-50

39. Pierce GF, Vande Berg J, Rudolph R, Tarpley J, Mustoe TA (1991) Platelet-derived growth factor-BB and transforming growth factor- $\beta 1$ selectively modulate glycosaminoglycan, collagen, and myofibroblasts in excisional wounds. Am J Pathol 138:629-646

40. Wieman TJ, Smiell JM, Su Y (1998) Efficacy and safety of a topical gel formation of recombinant human platelet-derived growth factor-BB (becaplemin) in patients with chronic neuropathic diabetic ulcers. A phase III randomized placebo-controlled doudle-blind study. Diabetes Care 21:822-827 
41. Higley HR, Ksander GA, Gerhardt CO, Falanga V (1995) Extravasation of macromolecules and possible trapping of transforming growth factor-beta in venous ulceration. Br J Dermatol 132:79-85

42. Trengove NJ, Staley MC, MacAuley S et al. (1999) Analysis of the acute and chronic wound environments: the role of proteases and their inhibitors. Wound Repair Regen 7:442-452

43. Descamps V, Blumenfeld N, Beuzard Y, Perricaudet M (1996) Keratinocytes as a target for gene therapy. Sustained production of erythropoietin in mice by human keratinocytes transduced with an adenoassociated virus vector. Arch Dermatol 132:1207-1211

44. Donahue BA, McArthur JG, Spratt SK et al., Boal D, Lagarde C, Sanchez L, Kaspar B-A, Sloan B-A, Lee Y-L, Danos O, Snyder R-O (1999) Selective uptake and sustained expression of AAV vectors following subcutaneous delivery. J Gene Med 1:31-42

45. Kessler PD, Podsakoff GM, Chen X et al. (1996) Gene delivery to skeletal muscle results in sustained expression and systemic delivery of a therapeutic protein. Proc Natl Acad Sci USA 93:14082-14087

46. Deodato B, Arsic N, Zentilin L et al. (2002) Recombinant AAV vector encoding human VEGF 165 enhances wound healing Gene Therapy 9:777-785

47. Sanlioglu S, Engelhardt J-F (1999) Cellular redox state alters recombinant adeno-associated virus transduction through tyrosine phosphatase pathways Gene Therapy 6(8): 1427-1437

48. Morgolis D-J, Cromobleholme T, Herlyn M (2000) Clinical protocol: Phase 1 trial to evaluate the safety of H5.020CMC.PDGF-B for the treatment of a diabetic insensate foot ulcer. Wound Repair Regen 8:480-493

49. Edmonds M, Bates M, Doxford M, Gough A, Foster A (2000) New treatments in ulcer healing and wound infection. Diabetes Metab Res Rev [Suppl 1]:S51-S54

50. Bello YM, Phillips TJ (2000) Recent advances in wound healing. JAMA 283:716-718 